Byshevets N, Stepanenko O. Managing cognitive activity of students in the information and educational environment of the institution of higher education in physical culture and sport. Theory and Methods of Physical education and sports. 2020; 1: 49-54

DOI: $10.32652 /$ tmfvs.2020.1.49-54
Бишевець Н, Степаненко О. Управління пізнавальною діяльністю студентів у інформаційно-освітньому середовищі закладу вищої освіти з фрізичної культури і спорту.

Теорія і методика фрізичного виховання і спорту. 2020; 1: 49-54 DOI: $10.32652 /$ tmfvs.2020.1.49-54

\title{
УПРАВЛІННЯ ПІЗНАВАЛЬНОЮ ДІЯЛЬНІСТЮ СТУДЕНТІВ У ІНФОРМАЦИЙНО-ОСВІТНЬОМУ СЕРЕДОВИЩІ ЗАКЛАДУ ВИЩОЇ ОСВІТИ 3 ФІЗИЧНОЇ КУЛЬТУРИ І СПОРТУ
}

\section{Наталія Бишевець, Ольга Степаненко}

Національний університет фізичного виховання і спорту України, Київ, Україна

\begin{abstract}
Анотація. Виявлено, що ефективність управління пізнавальною діяльністю учасників освітнього процесу безпосередньо залежить від ступеня поширення новітніх методів і прийомів передачі знань, технічних і технологічних нововведень, якості електронних освітніх ресурсів та готовності науково-педагогічного складу здійснювати професійну діяльність в умовах розвиненого інформаційного суспільства. Встановлено, що вдосконалення освітнього процесу в закладах вищої освіти з фрізичної культури та спорту ґрунтується на новітніх способах взаємодії суб'єктів освітнього процесу в рамках інформаційно-освітнього середовища закладу вищої освіти з фрізичної культури та спорту. Мета. Дослідити механізми взаємодії між суб'єктами освітньої діяльності в інформаційно-освітньому середовищі закладу вищої освіти з фізичної культури та спорту в процесі управління пізнавальною діяльністю студентів. Методи. Вивчення, аналіз, систематизація й узагальнення науково-методичної літератури та передового педагогічного й власного досвіду. Результати. Визначено, що спортивно-педагогічна інформація циркулює в закладі вищої освіти в цифровому вигляді, а до її характерних рис віднесено зв'язок із фрізкультурно-спортивною діяльністю, спрямованість на висвітлення аспектів розвитку фрізичної культури та спорту, сконцентрованість на фрізичних здатностях людини в русі. Розроблено схематичну модель трансляції знань, досліджено процес управління пізнавальною діяльністю студентів у рамках інформаційно-освітнього середовища закладу вищої освіти та визначено умови ефективного управління пізнавальною діяльністю студентів.
\end{abstract}

Ключові слова: інформація, освіта, технологія, знання, діяльність, потік, циркуляція, управління, взаємодія, мережа, передача.

\section{Natalia Byshevets, Olha Stepanenko \\ MANAGING COGNITIVE ACTIVITY OF STUDENTS IN THE INFORMATION AND EDUCATIONAL ENVIRONMENT OF THE INSTITUTION OF HIGHER EDUCATION IN PHYSICAL CULTURE AND SPORT}

\begin{abstract}
It is revealed that the effectiveness of managing cognitive activity of educational process participants directly depends on the degree of dissemination of new methods and techniques of knowledge transfer, technical and technological innovations, quality of electronic educational resources and readiness of scientific and pedagogical staff to carry out professional activity under conditions of developed information society. It is established that educational process improvement in institutions of higher education in physical culture and sport is based on the latest ways of the educational process subject interaction within the frames of information and educational environment of institutions of higher education in physical culture and sport. Objective. Investigate the interaction mechanisms between the subjects of educational activity in the information and educational environment of higher education institution in physical culture and sport in the process of managing the cognitive activity of students. Methods. Study, analysis, systematization and generalization of scientific and methodological literature and advanced pedagogical and personal experience. Results. It is determined that sports and pedagogical information circulates in higher education institution in digital form, and its characteristics include the connection with physical culture and sports activities, focus on highlighting aspects of physical culture and sport development, accent on human physical abilities in motion. A schematic model of knowledge transfer has been developed, the process of students' cognitive activity management within the frames of information and educational environment of a higher education institution has been studied and the conditions for effective management of students' cognitive activity have been determined. Keywords: information, education, technology, knowledge, activity, circulation, management, interaction, network,
\end{abstract} transfer.

Вступ. Стрімка інформатизація суспільства зумовила кардинальні зміни у системі вищої освіти, спричинила встановлення нових вимог до організації освітнього процесу в закладах вищої освіти (ЗВО), відтак інтеграція інформаційнокомунікаційних технологій (ІКТ) в діяльність освітніх систем забезпечила вільний доступ до інформації незалежно від місцеположення учас- 
ників й спростила освітню взаємодію між його суб'єктами, причому активне застосування сучасних мобільних телекомунікаційних засобів сприяло технічному забезпеченню поширення освітніх ресурсів [1, 22, 24]. Фактично сучасний 3ВО функціонуе в інформаційно-освітньому середовищі (IOC), де змістово-технологічна підтримка функціонування та розвитку IOC ЗВО здійснюється шляхом впровадження нових методів і форм управління освітнім закладом й розвитку його комунікативної інфраструктури, застосування автоматизованих систем управління освітнім процесом та експертноконсультативних систем, розробки електронних навчально-методичних комплексів для вивчення різних навчальних дисциплін [6, 12, 20, 21].

Сучасні фахівці активно розробляють інформаційні системи освітнього спрямування, сконцентровані на розробці моделей інформаційних процесів поширення знань, здійснюють теоретичні дослідження питань професійної підготовки майбутніх фахівців в умовах IOC, виконують моделювання процесів передачі знань, досліджують математичні моделі руху інформаційних потоків у 3ВО [1, 9, 16, 17]. Ученими вивчаються передумови створення й функціонування IOC для системи освіти $[6,7,12]$. Так, з точки зору М. О. Топузова [15], застосування засобів інформаційного моделювання на етапі його проектування дозволяє встановити й проаналізувати взаємопов'язані елементи освітньої системи.

У раховуючи проблеми, пов'язані зі створенням умов для реалізації індивідуалізованого навчання, Т. Л. Мазурок [10] запропонувала модель формування знань в автоматизованій системі управління педагогічною системою, де процес підготовки фахівця виражено структурно-логічною схемою, представленою нечітким орієнтованим графом. У результаті дослідження, В. Є. Ходаковим [17] розроблено алгоритм інформаційної моделі документообігу 3ВО, а А. М. Шелестовою [18] запропоновано застосовувати он-лайн сервіси як перспективні та альтернативні засоби навчання студентів, Р. Явічем [25] здійснено проектування методів навчання студентів у віртуальному освітньому середовищі.

Проблема створення, розвитку й функціонування IOC надзвичайно актуальна для ЗВО з фізичної культури і спорту, оскільки значна частка студентства залучена до активного спортивного життя, а використання елементів дистанційного навчання відкриває перспективи майбутнім фахівцям фізичного виховання та спорту засвоювати матеріал під час навчально-тренувальних зборів та активної змагальної діяльності [5]. Утім, попри окремі доробки [19], дослідження в даному напрямі не знайшли свого відображення в науковій літературі й не стали предметом широкого обговорення в наукових колах.

Дослідження виконано відповідно до плану НДР Національного університету фізичного вихо- вання і спорту України на 2016-2020 рр. за темою «Технологія проектування інформаційного середовища закладу вищої освіти з фізичної культури і спорту» (номер держреєстрації: 0119U000308).

Мета дослідження - уточнити поняття та дослідити механізми взаємодії між суб'єктами освітньої діяльності в IОС 3ВО з фізичної культури та спорту в процесі управління пізнавальною діяльністю студентів.

Методи дослідження: теоретичний аналіз, систематизація й узагальнення науково-методичної літератури та передового педагогічного і власного досвіду.

Результати дослідження та їх обговорення. Досліджуючи особливості IOC $3 \mathrm{BO}$ з фізичної культури та спорту, встановлено характерні відмінності його розвитку й функціонування. Насамперед IOC 3ВО фізкультурного профілю від IOC ЗВО іншого спрямування відрізняється змістом інформаційної складової та освітнього наповнення середовища. Крім того, як показує практичний досвід [19], специфічність контингенту тих, хто навчається, їхні потреби, зумовлені активним спортивним життям, необхідністю брати участь у навчально-тренувальних зборах та змагальна діяльність, вимагають своєрідних умов для забезпечення безперервності навчання, що диктує специфічні правила взаємодії між учасниками освітнього процесу в рамках IOC 3BO.

У структурі IOC ЗВО виділено змістову, організаційну й технологічну складові, де змістова складова містить інформаційний, освітній та науково-методичний компоненти, які в сукупності становлять віртуальний контент, організаційна містить систему інформаційного забезпечення, систему інформаційного маркетингу та підрозділи, які забезпечують функціонування IOC, зокрема адміністрація й методична служба, а технологічна включає апаратну підсистему, засоби масової інформації й комунікації та сервісну систему, що забезпечує обслуговування технічних засобів і охоплює інформаційний, освітній і дослідницький рівні [19].

Якщо організаційна й технологічна складові є типовими для IOC 3ВО, то змістова складова має свої характерні особливості залежно від професійного спрямування тих, хто навчається [13]. Так, специфічною рисою змістового наповнення складової IОС в ЗВО з фізичної культури і спорту є зв'язок системи знань з інформацією, якій властива спрямованість на висвітлення аспектів розвитку фізичної культури і спорту та сконцентрованість на фізичних здатностях людини в русі.

Досліджуючи феномен поняття «інформація», вивчаючи міркування вчених [14] про його тлумачення та пробуючи оцінити взаємозв'язок інформації зі знаннями, а також беручи до уваги трансформацію дефініції в різних концепціях розуміння природи інформації та різних підходів до іï визначення, встановлено складність і багатоаспектність його трактування. Отже, в подальшому в 
Освітні стандарти, розпорядження, накази, рішення, повідомлення, розклад, новини, бухгалтерський облік, звіти

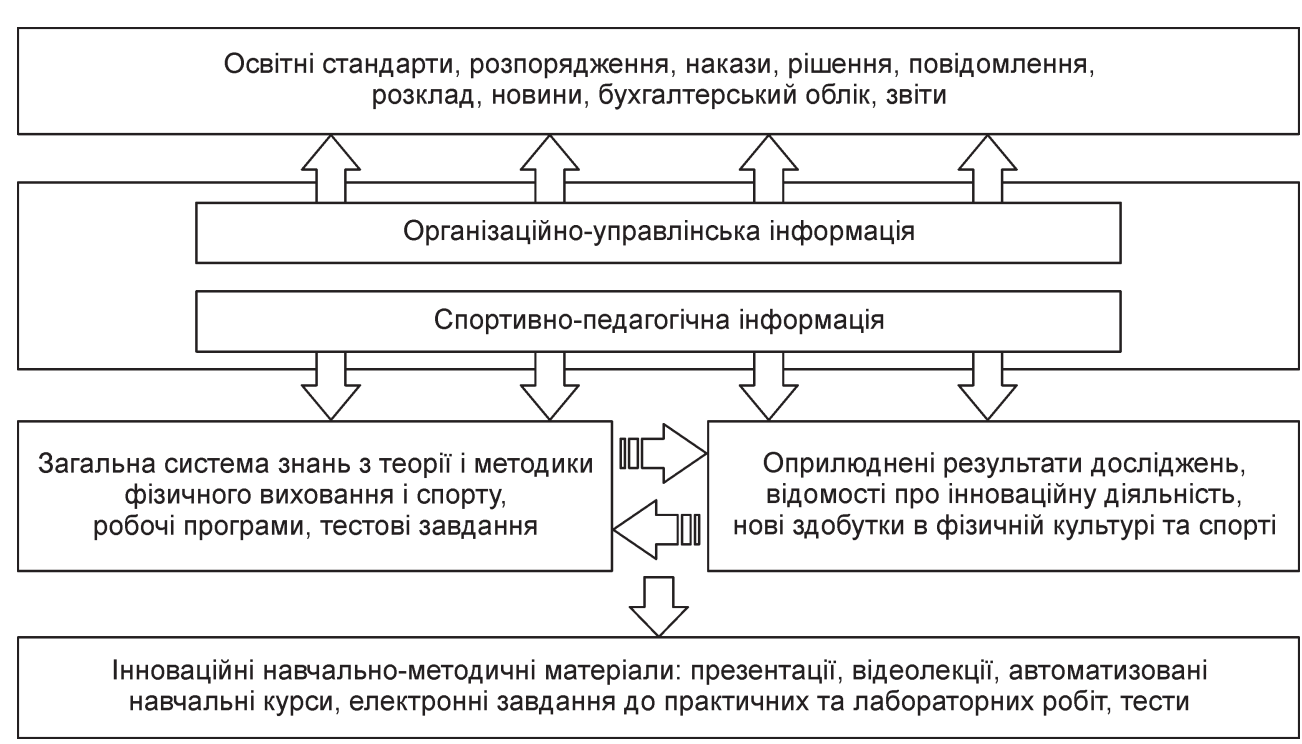

Рисунок 1 - Інформаційноосвітнє забезпечення в закладах вищої освіти з фізичної культури і спорту нноваційні навчально-методичні матеріали: презентації, відеолекції, автоматизовані навчальні курси, електронні завдання до практичних та лабораторних робіт, тести контексті забезпечення освітнього процесу в умовах функціонування IOC інформація розглядалася нами відповідно до кібернетичного підходу, а саме з точки зору ㄲï здатності усувати невизначеність знань про стан об'єктів або перебіг процесів.

Інформація, яка циркулює в рамках IOC 3ВО, складається 3 накопичених знань, оприлюднених результатів наукових досліджень, навчальнометодичного забезпечення, а також документів організаційно-управлінського характеру. Відповідно, для подальших досліджень виникла потреба у визначенні навчально-методичного забезпечення системи підготовки майбутніх фахівців фізичного виховання і спорту як інформації особливого виду.

Під спортивно-педагогічною інформацією надалі ми розуміли складову науково-технічної інформації [3], що циркулює в ЗВО з фізичної культури i спорту в цифровому вигляді, характерними рисами якої є її зв'язок із фізкультурно-спортивною діяльністю (рис. 1).

На основі спортивно-педагогічної інформації відбувається оновлення напрямів наукових досліджень, уточнюється категоріально-понятійний апарат, удосконалюються шляхи медичного й наукового забезпечення, розвивається, доповнюється, збагачується й модернізується загальна система знань, генеруються нові знання 3 теорії і методики фізичного виховання та спорту, які систематизуються, обробляються й поширюються в рамках IOC 3 BO у форматі інноваційних навчальнометодичних матеріалів.

Із огляду на сучасне розуміння інформаційної природи управління [2, 17, 23], рух спортивнопедагогічної інформації всередині IOC $3 \mathrm{BO} з$ фізичної культури та спорту та поза його межами через комунікаційні канали зв'язку можна розглядати як інформаційно-освітній потік.

Аналізуючи досвід моделювання процесів дистанційної передачі знань [16], нами побудовано схематичну модель управління пізнавальною ді- яльністю студента в IOC 3ВО, в якій за допомогою раціональних зв'язків представлено інформаційно-освітній потік передачі знань від джерела його формування - викладача - до споживача знань - студента, які транслюються через IКT (рис. 2).

Покажемо, яким чином відбувається процес управління пізнавальною діяльністю студентів у IOC $3 \mathrm{BO}$

Насамперед знання, накопичені викладачем, обробляються й подаються на електронних носіях або розміщуються у вигляді електронних освітніх ресурсів у інформаційно-телекомунікаційних системах, зокрема на електронній освітній платформі $3 \mathrm{BO}$.

Можливі два випадки: управління пізнавальною діяльністю студента $C_{1}$ здійснюється під час аудиторних занять; управління здійснюється дистанційно, наприклад, за умови, що студент $C_{2}$ перебуває на навчально-тренувальних зборах або змаганнях. Тоді студент $C_{1}$ отримує завдання за допомогою IКТ і в ході його виконання безпосе-

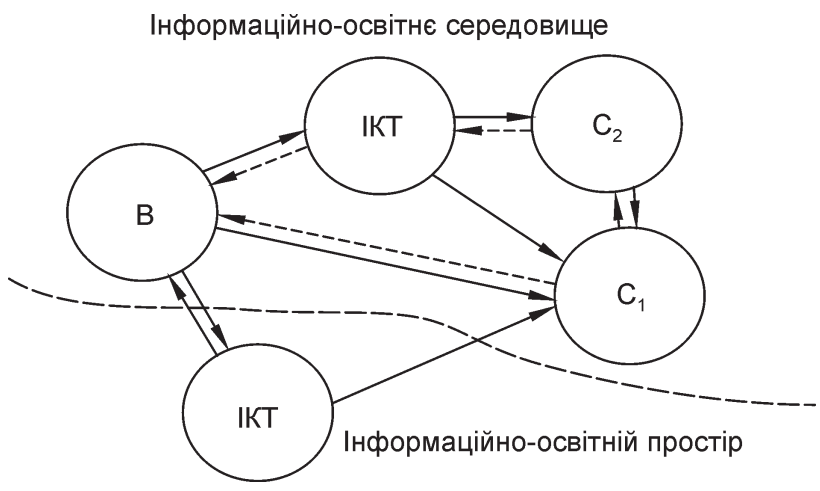

Рисунок 2 - Схематична модель управління пізнавальною діяльністю студента закладів вищої освіти:

$B$ - викладач, $C_{1}$ - студент, присутній на аудиторному занятті, $C_{2}-$ студент поза межами ЗВО, IKT - інформаційно-комунікаційні технології 
редньо взаємодіє з викладачем $B$, а в іншому педагогічний вплив і зворотний зв'язок відбуваються опосередковано за участі IКТ. Разом з тим, суб'єкти освітньої діяльності звертаються до відкритих освітніх ресурсів мережі Інтернет, причому викладач $B$, взаємодіючи 3 інформаційно-освітнім простором, не лише отримує нову інформацію, осмислює їі, розширюючи й поглиблюючи власні знання, породжуючи нові ідеї й відкриваючи недосліджені проблемні поля, а й розміщує результати власної навчально-методичної та науково-дослідної роботи й тим самим збагачує інформаційно-освітній простір. Водночас студенти $C_{1}$ i $C_{2}$ беруть участь в обміні знаннями, обговорюючи освітній матеріал, виконуючи спільні завдання, долучаються до колективних проектів, приєднуються до студентських груп. У цьому ракурсі за вхідні дані можна взяти знання викладача, а за вихідні - знання студента, сформовані під впливом педагогічних дій з боку викладача, які дозволяють студенту перейти на наступний освітній чи освітньо-кваліфікаційний рівень [8, 16].

Унаслідок дослідження виділено ряд вимог ефективного управління пізнавальною діяльністю студента в рамках IOC 3ВО, зокрема з фізичної культури і спорту:

- процеси накопичень знань учасників освітнього процесу є циклічними;

- суб'єкти освіти вмотивовані до сприйняття знань $з$ різних джерел;

- відбувається поєднання методів управління пізнавальною діяльністю студента згідно 3 його індивідуальною траєкторією навчання та поточними потребами;

- застосовуються найбільш доступні канали зв’язку між викладачем і студентом;

- освітні ресурси систематично оновлюються внаслідок взаємодії з інформаційно-освітнім простором.

Дискусія. У ході міркування над проблемами управління пізнавальною діяльністю студентів 3ВО з фізичної культури та спорту в межах IOC як процесу формування знань стало зрозумілим, що мова йде про специфічні знання в широкому розумінні, які покладені в зміст освіти майбутніх фахівців й у сумі становлять ядро професійних компетентностей випускника, затверджених у стандартах вищої освіти.

Вивчаючи праці науковців про природу інформації, ми помітили, що залежно від її спрямування вона класифікується як економічна, правова, статистична, соціологічна тощо. Тому виникло питання визначити інформацію, яка стосується підготовки фахівців з фізичної культури та спорту як таку, що має відмітні ознаки й володіє тільки їй властивими характеристиками. Аналіз літературних джерел показав, що наукова спільнота [2, 11, 12], плідно працюючи в напрямі інформаційного забезпечення освітнього процесу та наукових досліджень 3ВО, протягом тривалого часу опе- рує поняттями «спортивна інформація», «наукова спортивна інформація», «інформаційне забезпечення спортивної освіти». Попри неоднозначні й суперечливі погляди на сутність інформації, на які вказує О. А. Титенко [14], не претендуючи на остаточне вирішення, в нашому дослідженні ми зробили спробу виділити спортивно-педагогічну інформацію й за першої змоги здійснити її визначення. Утім докорінні зміни, що відбуваються в суспільстві й педагогіці, разом з розвитком науки зумовлюють необхідність подальшого вдосконалення понятійно-термінологічного апарату системи підготовки майбутніх фахівців 3 фізичного виховання і спорту.

Просуваючись далі, вивчаючи сприйняття руху інформації сучасними дослідниками [4], рух спортивно-педагогічної інформації всередині IOC 3ВО трактувався нами як внутрішній, а поза його межами - як зовнішній інформаційно-освітній потік.

Проблеми проектування, створення, розвитку й функціонування IOC перебувають у центрі уваги зарубіжних і вітчизняних дослідників. Одним 3 важливих питань в умовах розвиненого інформаційного суспільства $€$ удосконалення системи управління ланцюгом передачі знань, що передбачає вивчення й аналіз механізмів управління пізнавальною діяльністю студентів, яке ми розглядали в контексті управління інформаційно-освітніми потоками. На цьому етапі дослідження, для більш глибокого розуміння перебігу процесу управління пізнавальною діяльністю студентів в рамках IOC ЗВО, ми звернулися до його графічного представлення, що спрощує сприйняття, унаочнює зв'язки між елементами системи й дає можливість у майбутньому моделювати процеси передачі знань.

Висновки. Дослідження показало, що створення і розвиток IOC $3 \mathrm{BO}$ з фізичної культури та спорту спрямоване на забезпечення безперервного навчання студентів в умовах розвиненого інформаційного суспільства 3 урахуванням специфіки змісту освіти й контингенту, залученого до змагально-тренувальної діяльності.

Спортивно-педагогічна інформація як джерело змістового наповнення IOC $3 \mathrm{BO}$ з фізичної культури і спорту супроводжує весь процес навчання студентів як у формі інформаційних повідомлень, так і у формі знань, що становлять ядро змісту їхньої фахової підготовки. Рух спортивнопедагогічної інформації від джерел іiї концентрації до суб'єктів освітнього процесу за допомогою IКТ формує інформаційно-освітні потоки.

Унаочнення процесу управління пізнавальною діяльністю майбутнього фахівця з фізичного виховання та спорту у форматі схематичної моделі дозволяє унаочнити складну структуру відносин між викладачем, IКТ й студентом та розглядати педагогічний вплив на пізнавальну сферу студента як сукупність елементів освітнього процесу й зв'язків між ними. 
Установлено, що залежно від фізичної присутності студента на занятті, модернізуються способи взаємодії між суб'єктами освітньої діяльності.

Вільний доступ до знань поза межами IOC ЗВО $з$ фізичної культури та спорту на теренах інформаційно-освітнього простору відкриває можливості учасникам освітнього процесу розширюва- ти й поглиблювати знання, що оновлюються й генеруються.

Перспективи подальших досліджень полягають у вивченні проектування інформаційно-освітньої системи ЗВО з фізичної культури і спорту.

Конфлікт інтересів. Автори заявляють, що відсутній будь-який конфлікт інтересів.

\section{Література}

1. Бомба А, Назарук М, Пасічник В. Побудова дифузійноподібної моделі інформаційного процесу поширення знаннєвого потенціалу. Вісник Національного університету «Львівська політехніка». Комп'ютерні науки та інформаційні технології. 2014; 800: 35-44.

2. Єрмаков С. Стан та перспективи розвитку наукового інформаційного простору у вищих навчальних закладах фрізичної культури. Теорія і методика фрізичного виховання і спорту. 2006; 3: 89-93.

3. Закон України про інформацію. 1992. - № 48. - 650 с. - Режим доступу: https://zakon.rada.gov.ua/laws/ show/2657-12 (дата звернення: 20.02.2020)4. Іванова ОМ. Характеристика та класифікація інформаційних потоків підприємств. Економічна наука. 2016; 13: 18-22.

4. Іванова ОМ. Характеристика та класифрікація інформаційних потоків підприємств. Економічна наука. 2016; 13: 18-22.

5. Іващенко МВ, Бикова ТБ. Особливості використання елементів змішаного навчання в процесі викладання навчальних дисциплін у закладах вищої освіти. Фізико-математична освіта. 2018; 1(15): 221-6.

6. Кізім СС, Куцак ЛВ, Люльчак СЮ. Інформаційно-освітнє середовище як засіб модернізації професійної підготовки майбутніх фахівців. Фізико-математична освіта. 2017; 4(14): 37-42.

7. Кобися АП. Інфрормаційне освітнє середовище як платформа для реалізації змішаного навчання у вищих навчальних закладах. Інформаційні технології і засоби навчання. 2017; 1: 75-82.

8. Лудцев КБ, Лыгина НИ. Разработка информационной системы для проектирования индивидуальных образовательных траекторий. Современная техника и технологии. 2016; 5 [Електроний ресypc]. URL: http:// technology.snauka.ru/2016/05/10042 (дата звернення: 20.02.2020).

9. Любарець ВВ. Теорія і практика професійної підготовки майбутніх менеджерів соціокультурної діяльності в умовах інформаційно-освітнього середовища [автореферат]. 2019, Київ. 46 с.

10. Мазурок ТЛ. Модель формирования знаний для автоматизированной системы управления обучением. Образовательные технологии и общество. 2013; 16(1): 737-762.

11. Свистельник ИР. Информационное обеспечение профессионального образования в сфрере фризической культуры и спорта бывших стран СНГ. Слобожанський науково-спортивний вісник. 2016; 2(52): $107-111$.

12. Свістельник IP. Система наукової спортивної інфрормації: формування, розвиток, перспективи. Теорія та методика фрізичного виховання. 2005; 4: 2-5.

13. Сокуренко ВВ. Проектування інформаційно-освітнього середовища у вищих навчальних закладах зі специфічними умовами навчання. Публічне управління XXI століття: світові практики та національні перспективи. 2018. 467-71.

14. Титенко ОА. Інформація та знання як ключові поняття сучасної політичної економії. Науковий часопис НПУ імені М. П. Драгоманова. Серія 18: Економіка і право. 2015; 28: 43-50.

15. Топузов МО. Проектування інформаційно-освітнього середовища навчальних закладів у сучасному суспільстві. Український педагогічний журнал. 2017; 1: 26-36.

16. Ус ГО. Моделювання процесів передачі знань в системі дистанційної освіти у вищих навчальних закладах: [Електронний ресурс]. Ефективна економіка. 2014; 7. - Режим доступу: http://nbuv.gov.ua/-UJRN/ efek_2014_7_30 (дата звернення 20.02.2020)

17. Ходаков ВЕ, Козел ВН, Соколов АЕ. Математическая модель представления информационных потоков в виде ориентированных графов и их преобразования. Проблеми інформаційних технологій. 2016; 20: 73-83.

18. Шелестова АМ. Онлайн сервіси як перспективні та альтернативні засоби навчання студентів ВНЗ України. Бібліотекознавство. Документознавство. Інформологія. 2018; 2: 23-29.

19. Шинкарук ОА, Бишевець НГ, Яковенко ОО, Харченко ЛА. Інформаційно-освітнє середовище в системі підготовки фахівців з фрізичного виховання та спорту. Фізична культура спорт та здоров'я нації. 2019; 8(27). 367-374.

20. Atanasyan S. Methodology development and use of the information educational environment during the preparation of pedagogical high school students. Voronezh: scientific book, 2009. 152 p.

21. Aydar M, Kalimull, Zulhiza I. Islamova. Formation of Information - Educational Environment in the Partner Universities of University of Shanghai Cooperation Organization. Mathematics education. 2016; 11(6): $1879-90$.

22. Islamova Zl. Modernization processes of the university development in the context of integration of informatization and internationalization of vocational education. Teaching Bashkortostan journal. 2014; 1: 24-33.

23. Lee EA. The Problem with Threads. IEEE Computer. 2006; 39(5): 33-42.

24. Segev El. Google and the Digital Divide: The Biases of Online Knowledge. Oxford: Chandos Publishing, 2010.171 p.

25. Yavich R, Starichenko B. Design of Education Methods in a Virtual Environment. Journal of Education and Training Studies. 2016; 5(9): 176-86. 


\section{Literature}

1. Bomba A, Nazaruk M, Pasichnyk V. Designing a diffusion-like model of the information process of dissemination of knowledge potential. Visnyk natsionalnoho universytetu «Lvivska politekhnika». 2014; 800: 35-44.

2. lermakov S. Status and prospects of development of scientific information space in higher educational institutions of physical culture. Teoriia i metodyka fizvykhovannia i sportu. 2006; 3: 89-93.

3. Law of Ukraine on information. 1992. - N 48. - 650 p. - Access mode: https://zakon.rada.gov.ua/laws/ show/2657-12 4. Ivanova OM. Characteristics and classification of information flows of enterprises. Ekonomichna nauka. 2016; 13: 18-22.

4. Ivanova OM. Characteristics and classification of enterprise information flows. Ekonomichna nauka. 2016; 13: 18-22.

5. Ivashchenko MV, Bykova TB. Features of the use of mixed learning elements in teaching of academic disciplines in higher education institutions. Fizyko-matematychna osvita. 2018; 1(15): 221-6.

6. Kizim SS, Kutsak LV, Liulchak SI. Information and educational environment as a means of modernizing the training of future professionals. Fizyko-matematychna osvita. 2017; 4(14): 37-42.

7. Kobysia AP. Information educational environment as a platform for the implementation of mixed learning in higher education institutions. Informatsiyni tekhnolohii i zasoby navchannia. 2017; 1: 75-82.

8. Ludtsev KB, Lygina NI. Development of information system for the design of individual educational trajectories. Sovremennaya tekhnika i tekhnologiya. 2016; 5 [Electronic resource]. URL: http://technology.snauka. ru/2016/05/10042 9. Liubarets VV. Theory and practice of professional training of future managers of socio-cultural activities in the information and educational environment [author's abstract]. 2019, Kyiv. 46 p.

10. Mazurok TL. Model for knowledge formation for automated system of education management. Obrazovatelnyye tekhnologiyi i obshchestvo. 2013; 16(1): 737-762.

11. Svistelnik IR. nformation support of professional education in the field of physical culture and sport of the former CIS countries. Slobozhanskyi naukovo-sport. Visnyk. 2016; 2(52): 107-111.

12. Svistelnik IR. System of scientific sports information: formation, development, prospects. Teoriia i metodyka fizvykhovannia. 2005; 4: 2-5.

13. Sokurenko VV. Designing information and educational environment in higher education institutions with specific learning conditions. Public administration of the XXI century: world practices and national perspectives.. 2018. 467-71.

14. TytenkoOA. Informationand knowledgeaskey concepts of modern politicaleconomy. Naukovyichasopys Natsionalnoho pedahohichnoho universytety imeni M. P. Drahomanova. 2015; 28: 43-50.

15. Topuzov MO. Designing the information and educational environment of educational institutions in modern society. Ukrainskyi pedahohichnyi zhurnal; 1: 26-36.

16. Us HO. Modeling of knowledge transfer processes in the system of distance education in higher educational institutions: [Electronic resource]. 2014; 7. - Access mode: http://nbuv.gov.ua/-UJRN/efek_2014_7_30

17. Khodakov VE, Kozel VN, Sokolov AE. Mathematical model of information flows representation in the form of oriented graphs and their transformation. Issues of information technologies. 2016; 20: 73-83.

18. Shelestova AM. Online services as promising and alternative means of teaching students of Ukrainian universities. Bibliotekoznavstvo. Dokumentoznavstvo. Informolohiia. 2018; 2: 23-29.

19. Shynkaruk OA, Byshevets NH, lakovenko OO, Kharchenko LA. Information and educational environment in the system of training specialists in physical education and sport. Fizychna kultura, sport ta zdorovia natsii. 2019; 8(27). 367-374.

20. Atanasyan S. Methodology development and use of the information educational environment during the preparation of pedagogical high school students. Voronezh: scientific book, 2009. 152 p.

21. Aydar M. Kalimull, Zulhiza I. Islamova. Formation of Information - Educational Environment in the Partner Universities of University of Shanghai Cooperation Organization. Mathematics education. 2016; 11(6): $1879-90$.

22. Islamova Zl. Modernization processes of the university development in the context of integration of informatization and internationalization of vocational education. Teaching Bashkortostan journal. 2014; 1: 24-33.

23. Lee EA. The Problem with Threads. IEEE Computer. 2006; 39(5): 33-42.

24. Segev El. Google and the Digital Divide: The Biases of Online Knowledge. Oxford: Chandos Publishing, 2010. 171 p.

25. Yavich R, Starichenko B. Design of Education Methods in a Virtual Environment. Journal of Education and Training Studies. 2016; 5(9): 176-86.

Надійшла 25.02.2020

\section{Інформація про авторів}

Бишевець Наталія Григорівна, http://orcid.org/0000-0001-6118-6580 bishevets@ukr.net

Степаненко Ольга Олексіївна, https://orcid.org/0000-0002-1415-2916 olenkast17@gmail.com

Національний університет фрізичного виховання і спорту України, 03150, Київ, вул. Фізкультури, 1

\section{Information about the authors}

Byshevets Nataliia, http://orcid.org/0000-0001-6118-6580 bishevets@ukr.net

Stepanenko Olha, https://orcid.org/0000-0002-1415-2916 olenkast17@gmail.com

National University of Ukraine on Physical Education and Sport, 03150, Kyiv, Fizkul'tury str., 1. 